\title{
Brown Root Rot Disease of Phyllanthus myrtifolius: The Causal Agent and Two Potential Biological Control Agents
}

\author{
Ka-Tung Leung, ${ }^{1,2}$ Chi-Yu Chen, ${ }^{1}$ Bang-Jau You, ${ }^{3}$ Miin-Huey Lee, ${ }^{1,2, \dagger}$ and Jenn-Wen Huang ${ }^{1, \dagger}$ \\ ${ }^{1}$ Department of Plant Pathology, National Chung Hsing University, Taichung 402, Taiwan \\ ${ }^{2}$ Advanced Plant Biotechnology Center, National Chung Hsing University, Taichung 402, Taiwan \\ ${ }^{3}$ School of Chinese Pharmaceutical Sciences and Chinese Medicine Resources, China Medical University, Taichung, Taiwan
}

\begin{abstract}
Brown root rot (BRR), caused by Phellinus noxius (Corner) G. Cunningham, occurs on over 200 species of plants, especially woody trees and shrubs. Ceylon myrtle (Phyllanthus myrtifolius [Wight] Müll.Arg.), a common hedge plant, was recently observed to be infected with BRR. Disease diagnosis was performed by completing Koch's postulates, and Ceylon myrtle was confirmed to be a new host of $P$. noxius. Typical symptoms of BRR were observed, including reduction in leaf size, dieback of branches, and suspended growth of young leaves. A disease severity index was used to quantify BRR in this study. Compared with Malabar chestnut, Ceylon myrtle was relatively resistant to BRR. Sur-

noxium based on $P$. noxius. Therefore, to temporarily distinguish these pathogens, the former clade was designated GPN (global P. noxius), whereas the latter clade was designated CPN (China Py. noxium). In biocontrol assays, Streptomyces padanus and Bacillus sp. were selected for BRR control of Ceylon myrtle. Disease severity was reduced from 0.51 to 0.37 by $S$. padanus and to 0.14 by Bacillus sp. in greenhouse trials. In addition, the two biocontrol agents, especially $S$. padanus, exhibited good growth-promoting effects on cuttings of Ceylon myrtle. With these double advantages, S. padanus and Bacillus sp. have great potential to control BRR in practical applications.
\end{abstract} prisingly, phylogenetic analysis of the ITS and $28 \mathrm{~S}$ sequences revealed that isolates identified as $P$. noxius from Taiwan and many other countries were clustered in the same clade but separate from the clade comprising isolates from China, which were designated Pyrrhoderma
Keywords: brown root rot, shrub, Phellinus noxius, Pyrrhoderma noxium, biocontrol, Ceylon myrtle, Phyllanthus myrtifolius
Infection of plants by root rot pathogens can consequently lead to wilting and death. Among those pathogens, Phellinus noxius (Corner) G. Cunningham is one of the main killers of perennial dicots. $P$. noxius causes brown root rot (BRR) disease in over 200 tree species and has a worldwide distribution, including tropical and subtropical areas in Southeast and East Asia, Oceania, Central America, and Africa (Akiba et al. 2015; Ann et al. 2002; Chung et al. 2015; Huang et al. 2016; Wu et al. 2011). The hosts of $P$. noxius include many economically important trees, such as loquat, longan, litchi, wax apple, lemon, camphor, banyan, Malabar chestnut, and pine (Ann and Ko 1992; Ann et al. 1999a, 1999b, 2002; Sahashi et al. 2010; Tsai et al. 2017). When trees are infected by $P$. noxius, disease symptoms progress from foliar chlorosis and leaf thinning to defoliation and decline rapidly over a few months or slowly over several years (Ann et al. 1999a, 2002; Chung et al. 2017). The early stage of the infection is symptomless and difficult to identify. However, once the infection progresses, the trees seldom survive. No known treatment is able to control infected trees completely.

Current address for K.-T. Leung: Tree Management Office, Diocesan Boys' School, 131 Argyle Street, MongKok, Kowloon, Hong Kong.

${ }^{\dagger}$ Corresponding authors: M.-H. Lee; mhlee@nchu.edu.tw and J.-W. Huang; jwhuang@nchu.edu.tw

Funding: This work was financially supported by the Advanced Plant Biotechnology Center from The Featured Areas Research Center Program within the framework of the Higher Education Sprout Project by the Ministry of Education in Taiwan.

*The $\boldsymbol{e}$-Xtra logo stands for "electronic extra" and indicates there are supplementary materials published online.

The author(s) declare no conflict of interest.

Accepted for publication 19 April 2020.

(C) 2020 The American Phytopathological Society
P. noxius, originally described as Fomes noxius by Corner (1932) from diseased rubber trees (Hevea brasiliensis), belongs to the family Hymenochaetaceae, order Hymenochaetales, and phylum Basidiomycota. $P$. noxius is characterized by the production of resupinate or bracket-shaped basidiocarps, which are rarely observed in nature. Instead, immature fruiting bodies appearing as mycelial mats without the formation of basidiospores are commonly present at the bases of infected trees (Ann et al. 1999a; Hattori et al. 1996; Chang 1992, 1995). However, when cultured on sawdust contained in plastic bags, this fungus can form thin, hard, and uneven basidiocarps with basidiospores, similar to those found in nature (Ann and Ko 1992; Ann et al. 1999a, 2002). When cultured on potato dextrose agar (PDA), this fungus produces irregular dark brown lines or patches (Ann et al. 2002). In addition, characteristic trichocysts and arthrospores can be observed in axenic culture (Ann et al. 2002). Narrow setal hyphae can be found on the basidiocarp, which is an important feature to distinguish $P$. noxius from the closely related species $P$. lamaensis (Holliday 1995). In addition to culture characteristics and fungal morphology, molecular markers, such as the internal transcribed spacer (ITS) sequence, $28 \mathrm{~S}$ sequence, and microsatellites, are often used for the identification and population genetic analysis of this pathogen (Chung et al. 2015; Tsai et al. 2017; Zhou et al. 2018). Recently, according to the phylogenetic analysis based on 28S and ITS sequences, $P$. noxius was moved to a newly established genus, $P y r$ rhoderma (Zhou et al. 2018). However, the displacement of Py. noxium was based on specimens from fallen unidentified trunks in Hainan, China, without referring to the type material. We would like to determine whether the fungus obtained from BRR is conspecific with the fungus from Hainan, China, and if the new name Py. noxium can be applied to the pathogen causing BRR in Taiwan.

Once a tree is infected by $P$. noxius, several treatments can be applied to control the disease, such as fungicide application, fumigation, flooding, trenching, and the removal of diseased plant residues (Chang 1996; Forestry Bureau, COA 2013; Tsai et al. 2005). Chemical fungicide application and fumigation with ammonia (Chang and Chang 1999) are the major approaches to control $P$. noxius in Taiwan. Fumigation with dazomet to disinfect the soil from which severely affected trees were removed has also been 
recommended to eradicate the inoculum (Fu et al. 2012). Several fungicides, including phosphorous acid, propiconazole, and prochloraz, were demonstrated to be effective in controlling the disease on seedlings of sugar apple and loquat (Tsai et al. 2005). Biocontrol with natural microorganisms is a common alternative approach for plant disease control. There have been studies on the biological control of BRR disease (Burcham et al. 2017; Chou et al. 2019; Ribera et al. 2016; Schwarze et al. 2012; Shih et al. 2013; Zhao et al. 2011; Wu et al. 2014), but most of them were conducted in vitro. Streptomyces sp. (Shih et al. 2013) and Bacillus sp. (Zhao et al. 2011 ) could inhibit the growth of $P$. noxius in vitro, whereas Trichoderma species were tested in vitro and in planta (Burcham et al. 2017; Chou et al. 2019; Ribera et al. 2016; Schwarze et al. 2012). A recent study showed that pretreatment with Trichoderma asperellum prevented the wilting of $P$. noxius-inoculated loquat cuttings in greenhouse trials (Chou et al. 2019).

Ceylon myrtle (Phyllanthus myrtifolius [Wight] Müll.Arg.) is a shrub belonging to the family Euphorbiaceae. Being highly tolerant of drought and shade, Ceylon myrtle is frequently used in urban horticulture as a hedge plant and is often planted under tree canopies. In 2017, three Chinese banyans (Ficus microcarpa L. f.), growing alongside the old building of the Precision Engineering Institute on the campus of National Chung-Hsing University, were killed by BRR and exhibited characteristic signs of the fungus $P$. noxius. Under the shade of the Chinese banyans were dead and diseased Ceylon myrtles. It is likely that the disease of the Ceylon myrtles was caused by the same pathogen affecting the Chinese banyans. With regard to BRR disease control, prevention has generally been the only known effective strategy as opposed to curative approaches. To obtain effective biocontrol agents, we screened over 50 bacterial isolates in vitro for their activity against $P$. noxius, and two biocontrol agents were selected and applied in planta to evaluate their efficacy in protecting Ceylon myrtle from $P$. noxius infection.

Taken together, the aims of this study were (i) to fulfill Koch's postulates and prove that Ceylon myrtle is a new host of the BRR pathogen; (ii) to determine the taxonomic identity of the fungus causing BRR in Taiwan; (iii) to investigate the disease severity of BRR disease on Ceylon myrtle; and (iv) to select effective biocontrol agents to protect seedlings of Ceylon myrtle from BRR disease.

\section{Materials and Methods}

Isolation and cultivation of the pathogen. Diseased root or wood tissue was collected from under mycelium mats. Small pieces $(5 \times 2 \times$ $1 \mathrm{~mm}$ ) were removed from diseased tissues, surface sterilized with $0.5 \% \mathrm{NaClO}$ for $1 \mathrm{~min}$, rinsed with sterile water, and placed on semiselective PDA (Difco PDA supplied with 100 ppm of streptomycin sulfate and $10 \mathrm{ppm}$ of benomyl) (Tsai et al. 2017). The plates were then incubated at $28^{\circ} \mathrm{C}$. The edges of fungal mycelia growing from the diseased tissue were cut and transferred onto fresh PDA. For storage, 7- to 10-day cultures were cut into plugs with a 5-mm cork borer, and the mycelial plugs were placed into a $1.5-\mathrm{ml}$ centrifuge tube containing sterile water and kept at room temperature. To produce fruiting bodies in culture, the fungus was cultured in a plastic bag containing sawdust medium as described previously (Ann et al. 1999a). After 1 month of cultivation, the plastic bag was cut with a surgical knife to generate an opening with a length of $1 \mathrm{~cm}$ and then moved to a moisture chamber. The fruiting body could grow out from the opening.

Scanning electron microscopy (SEM). To examine the surfaces of the fungal structures at high resolution, SEM was performed. Before SEM, the selected samples underwent a preparation that included fixation, dehydration, and coating. For fixation, samples were immersed in $2.5 \%$ glutaraldehyde (diluted with cacodylate buffer) overnight at room temperature. Subsequently, the samples were dehydrated in a series of ethanol solutions $(30,50,70,80$, 90 , and $95 \%$ ) followed by being thrice dehydrated in $100 \%$ ethanol for 10 to $15 \mathrm{~min}$ for each immersion. The dehydrated samples were further dried by conducting critical point drying using liquefied carbon dioxide. The dried samples were then mounted on aluminum specimen stubs and coated with gold using a sputter coater. The prepared samples were examined under scanning electron microscopy (SEM, Topcon).

DNA extraction. The fungal strain was grown on PDA covered with a sheet of cellophane and incubated at $28^{\circ} \mathrm{C}$ for 1 week. Mycelia $(0.1 \mathrm{~g})$ were harvested by gently scratching the cellophane surface and were placed in a $1.5-\mathrm{ml}$ centrifuge tube. The mycelia were then crushed into powder using a grinder tube with liquid nitrogen. One microliter of preheated $\left(65^{\circ} \mathrm{C}\right) \mathrm{CTAB}$ buffer $(2 \%$ hexadecyltrimethylammonium bromide, $1.4 \mathrm{M} \mathrm{NaCl}, 20 \mathrm{mM}$ EDTA, $100 \mathrm{mM}$ Tris$\mathrm{HCl}, \mathrm{pH}$ 8.0) with fresh addition of $0.2 \% \beta$-mercaptoethanol was applied to the mycelial powder. The mixture was vortexed for $30 \mathrm{~s}$ and then incubated at $65^{\circ} \mathrm{C}$ for $10 \mathrm{~min}$. The mycelial debris was removed by centrifugation, and the supernatant was extracted with chloroform-isoamyl alcohol $(24: 1, \mathrm{v} / \mathrm{v})$ and then centrifuged at $12,000 \times g$ for $2 \mathrm{~min}$. The aqueous phase was collected, and $0.7 \mathrm{vol}-$ umes of isopropanol were added to precipitate the nucleic acids. The precipitated DNA was washed with $500 \mu \mathrm{l}$ of 75 and $100 \%$ ethanol and resuspended in $20 \mu \mathrm{l}$ of sterile Milli-Q water containing $0.1 \mu \mathrm{l}$ of RNase A $(10 \mathrm{mg} / \mathrm{ml})$. The concentration of DNA was determined based on the optical density (OD) at $260 \mathrm{~nm}$ by using a spectrophotometer (V-630 BIO, JASCO, Japan) (Tzean et al. 2016).

Molecular detection and phylogenic analysis. By using polymerase chain reaction (PCR), the 28S and ITS (ITS1-5.8S-ITS2) regions were amplified with the primer pairs LR0R and LR5 (Vilgalys and Hester 1990) and ITS1 and ITS4 (White et al. 1990), respectively. For specific detection of $P$. noxius, the primer pair G1F (5'-GCCCTTTCCTCCGCTTATTG-3') and G1R (5'CTTGATGCTGGTGGGTCTCT- $3^{\prime}$ ) was used to amplify a specific 653-bp DNA fragment within the ITS region by PCR (Wu et al. 2009). The PCR procedure was as follows: initial denaturation at $94^{\circ} \mathrm{C}$ for $2 \mathrm{~min}$, followed by 30 cycles of $94^{\circ} \mathrm{C}$ for $30 \mathrm{~s}, 50^{\circ} \mathrm{C}$ (28S) $/ 55^{\circ} \mathrm{C}$ (ITS) for $30 \mathrm{~s}$, and $68^{\circ} \mathrm{C}$ for $30 \mathrm{~s}$, and a final extension at $68^{\circ} \mathrm{C}$ for $5 \mathrm{~min}$. PCR products were verified by agarose gel electrophoresis and then purified with a Plus PCR Clean-Up Kit (GeneMark Bio, Taiwan). The DNA sequencing service was provided by the Biotechnology Center of National Chung Hsing University (NCHU).

The ITS and 28S sequences of isolates obtained from BRR in this study were used for phylogenetic analyses (Table 1). The following additional sequences obtained from GenBank were included (Supplementary S1): sequences of isolates obtained from BRR cases in Taiwan by Tsai et al. (2017) and Chung et al. (2017); three ITS sequences of isolates from rubber tree in Malaysia because the original description of $P$. noxius was from rubber tree $(H$. brasiliensis) in Malaysia (Ann et al. 2002); sequences of Pyrrhoderma and Fulvoderma species described by Zhou et al. (2018), of which the sequences of Fulvoderma species served as an outgroup. ITS sequences and 28S sequences were imported into MEGA X software. Multiple alignments were performed by using ClustalW. Phylogenetic relationships were analyzed by using the construct/test maximum likelihood tree method with 1,000 bootstrap replicates. Both tools were built-in functions of MEGA X (Kumar et al. 2018).

Cutting propagation and inoculation of Ceylon myrtle. One- or 2-year-old branches with diameters larger than $5 \mathrm{~mm}$ were cut from a healthy mother plant. Each branch was cut into a 10-cm segment, and the unnecessary shoots were removed, leaving two to three twigs on the upper half of the segment with six to 10 mature leaves. The cuttings were then planted on different combinations of peat, sand, and/ or Akadama soil mixed substrate to test the cutting propagation efficacy and to grow to seedlings for the inoculation assay. A mixture of Akadama soil and peat $(2: 1, \mathrm{vol} / \mathrm{vol})$ was used as a rooting substrate for the stem cuttings and generated over $90 \%$ of the seedlings. Threemonth-old seedlings with four to five branches were used in the inoculation assay as described below.

For inoculum preparation, wheat grain spawn of $P$. noxius isolate PB01 was prepared to establish the inoculation assay and to complete Koch's postulates. After thorough rinsing and cleaning, $50 \mathrm{~g}$ of wheat grains was soaked in flowing water overnight. The grains were then put into a 500-ml flask, covered with a layer of aluminum foil, 
and autoclaved. A 5-day cultured $P$. noxius colony was cut into $1 \times 2$ $\mathrm{cm}$ agar blocks. Ten agar blocks were placed into the flask and incubated in an incubator at $28^{\circ} \mathrm{C}$ for 2 weeks to generate grain spawns.

In addition, another type of spawn was prepared. Sawdust used for mushroom cultivation was mixed with rice bran, water, and $\mathrm{CaCO}_{3}$ (70:10:20:1, w/w/v/w) and placed into a plastic bag $(7 \times 9$ inches $)$ capped with a special cap designed for commercial mushroom cultivation. Wheat grain inoculum prepared as mentioned above was inoculated into a sterilized mixture of sawdust, rice bran, water, and $\mathrm{CaCO}_{3}(10 \mathrm{~g} / \mathrm{bag})$ and incubated at $28^{\circ} \mathrm{C}$ for 1 month. This was designated sawdust spawn.

For inoculation, experiments were conducted mainly according to previous studies (Ann et al. 1999b; Sahashi et al. 2010). Approximately 10 -week-old seedlings, each planted in a pot (3 inches in diameter), were used for inoculation. For root inoculation, the surface soil $(2$ to $3 \mathrm{~cm})$ of each plant was removed, and approximately $1.0 \times$ $0.2 \mathrm{~cm}$ of the entire bark of the tap root was removed at two positions with a sterile knife. Forty grams of sawdust spawn was placed on the injured tap root, and the plant root system was covered again with soil. Seedlings inoculated with sterile sawdust mixture were used as controls (Sahashi et al. 2010). For stem base inoculation, the stem base of the seedlings was exposed, surface sterilized with $70 \%$ alcohol, and scraped gently to remove the epidermis $(1.5 \mathrm{~cm} \times 2 \mathrm{~mm})$. Two grams of grain spawn was placed on the scraped portion of the stem base and wrapped with a sheet of plastic tape. Seedlings inoculated with sterile wheat were used as controls (Ann et al. 1999b). All seedlings were incubated in a greenhouse for 4 months. Four to five seedlings were used for each inoculation treatment, and the experiment was performed twice.

Stem-base-inoculated Ceylon myrtles by $P$. noxius isolate PB01 were used to investigate disease severity. Based on the appearance of disease symptoms, the disease severity of all seedlings was divided into six levels. Level 0 indicated a healthy plant. Levels 1 to 4 were set based on the percentage of canopy lost and symptom appearance. Level 5 indicated plant death. The following formula was used to calculate the disease severity index:

$$
\text { DSI }=\frac{n_{0} \times 0+n_{1} \times 1+n_{2} \times 2 \ldots n_{5} \times 5}{N \times 5}
$$

where DSI is the disease severity index, $n$ is the total number of seedlings in each level, and $N$ is the total number of seedlings.

To monitor the mortality of the inoculated seedlings, 3-weekcultured grain spawns of $P$. noxius FA01, PB01, or TC10 were inoculated onto 2- to 3-month-old seedlings of Ceylon myrtle and Malabar chestnut (Pachira macrocarpa [Cham. \& Schltdl.] Walp.) by the stem-base inoculation method as mentioned above, with four replicates for each treatment. Sterilized wheat grains served as a control. The experiment was performed twice, and disease severity was evaluated as mentioned above.

Biocontrol agent selection and cultural broth preparation. To select effective microbes that can control BRR pathogens, antibiosis was used as a selection criterion. In total, 52 candidate bacterial strains were tested. Antibiotic activity was evaluated using a dual culture assay. $P$. noxius isolates PB01 and TC10 were used as targets for the screening. P. noxius was cultured on PDA plates $(90 \mathrm{~mm}$ in diameter) for 4 days, and then an agar block ( $6 \mathrm{~mm}$ in diameter) cut from the outer colony edge was transferred to the center of a PDA plate. The bacterial biocontrol agent was inoculated onto the PDA plate by streaking a line of $2 \mathrm{~cm}$ in length that was $3 \mathrm{~cm}$ away from the center of the plate. On the opposite side of the same plate and at the same distance from the center, sterile water served as the control. The radius of the growth-inhibited area was recorded at 5 days postinoculation. Two bacterial strains, Bacillus sp. BB118 and S. padanus PMS-702, displayed strong antibiotic activity and were selected and cultured in liquid medium to evaluate their efficacy in BRR disease control in greenhouse trials. S. padanus PMS-702 has been previously used to control various diseases (Huang et al. 2007; Shih et al. 2003), whereas BB118 was isolated and identified in this study. The identification was performed by PCR amplification of the 16S rRNA gene using the primer pair 27S and 1492R (Lane 1991), and the sequence (accession no. MN960113) was used to blast the NCBI database with BLASTn and the EzBioCloud 16S database (EzBioCloud.net).

Liquid SSM medium ( $2 \%$ soybean meal, $0.5 \%$ molasses, $1 \%$ surimi, $0.5 \%$ yeast extract, and $1 \% \mathrm{NaCl}$ ) and SMGC-2 medium (1.1\% soybean meal, $1.1 \%$ glucose, $1 \%$ coconut oil, and $0.05 \%$ $\mathrm{CaCO}_{3}$ ) were used to culture Bacillus sp. BB118 and S. padanus PMS-702, respectively. To prepare the culture broth for Bacillus sp. BB118, a single colony of 3-day-cultured Bacillus sp. BB118 on nutrient agar (HiMedia Lab) was transferred into sterile water. The suspension was adjusted to $\mathrm{OD}_{600}=0.8\left(1 \times 10^{9} \mathrm{CFU} / \mathrm{ml}\right)$, and $1 \mathrm{ml}$ was inoculated into a 500-ml flask containing $100 \mathrm{ml}$ of $\mathrm{SSM}$ broth. The flask was then incubated at $28^{\circ} \mathrm{C}$ on a shaker at $120 \mathrm{rpm}$ for 3 days. To prepare the culture broth of $S$. padanus PMS-702, spores were collected from 7-day-cultured S. padanus PMS-702 on ISP medium- 4 (HiMedia Lab) with $0.05 \%$ Tween 20 solution. The suspension was adjusted to $\mathrm{OD}_{620}=1.08\left(4 \times 10^{8}\right.$ $\mathrm{CFU} / \mathrm{ml}$ ), and $1 \mathrm{ml}$ was inoculated into a flask containing $100 \mathrm{ml}$ of SMGC-2 broth. The flask was then incubated at $28^{\circ} \mathrm{C}$ on a shaker at $120 \mathrm{rpm}$ for 5 days.

BRR disease control assay on Ceylon myrtle seedlings in a greenhouse. Fresh cuttings of Ceylon myrtle were used, and a three-layer planting medium was designed for the assay. Akadama soil was first mixed with peat and perlite 2:1:0.5 (v/v/v) as the planting substrate. The planting substrate was then mixed with sawdust spawn at a ratio of $1: 1(\mathrm{v} / \mathrm{v})$ to prepare the $P$. noxius-inoculated substrate. $P$. noxius-inoculated substrate was added to the bottom of a 16 -mesh net-covered plastic tray $(27 \times 23 \times 7 \mathrm{~cm})$ to a 2 -cm depth, a 1-cm depth of sawdust spawn was added as the middle layer, and a 2 -cm depth of planting substrate was placed on the top. To evaluate the protective effect and plant growth promotion effect of the biocontrol agents in planta, cuttings of Ceylon myrtle were soaked in a 10fold or 50-fold dilution of culture broth for $20 \mathrm{~min}$ and then planted to a $2.5 \mathrm{~cm}$ depth into the middle layer. For the plant growth promotion assay, the middle layer as mentioned above was replaced with pathogen-free sawdust. Twelve cuttings of each treatment were evenly planted in three rows. All trays were placed in a greenhouse at 25 to $30^{\circ} \mathrm{C}$ for 8 weeks. Then, all seedlings were uncovered and allowed to develop to different growth levels and disease levels, based on their shoot and root growth status and disease symptoms, respectively. The disease severity index and growth index were calculated using the formula mentioned above. The experiment was

Table 1. Isolates of Phellinus noxius isolated in this study and used for ITS and 28S sequencing

\begin{tabular}{|c|c|c|c|c|c|}
\hline \multirow[b]{2}{*}{ Isolates } & \multirow[b]{2}{*}{ Species identification } & \multirow[b]{2}{*}{ Geographic origin } & \multirow[b]{2}{*}{ Host } & \multicolumn{2}{|c|}{ Accession number } \\
\hline & & & & ITS & $28 S$ \\
\hline FA01 & $\mathrm{GPN}^{\mathrm{a}}$ & NCHU, Taichung & Ficus microcarpa & MN945438 & $\ldots$ \\
\hline FA03 & GPN & NCHU, Taichung & Ficus microcarpa & MN945440 & $\ldots$ \\
\hline PB01 & GPN & NCHU, Taichung & Phyllanthus myrtifolius & MN945441 & MN963333 \\
\hline $\mathrm{TC} 02$ & GPN & Xitun, Taichung & Ficus microcarpa & MN945442 & MN963330 \\
\hline TC06 & GPN & NCHU, Taichung & Melia azedarach & MN960110 & MN963331 \\
\hline $\mathrm{TC} 10$ & GPN & Dadu, Taichung & Ficus microcarpa & $\ldots$ & MN963332 \\
\hline
\end{tabular}

${ }^{a}$ GPN = global Phellinus noxius, and NCHU = National Chung Hsing University. 
performed twice independently in the greenhouse. Water treatment was used as a negative control in the two trials. The commercial root growth stimulator 2-(1-naphthyl) acetamide $(0.02 \%)$ was used as a positive control treatment in the second greenhouse trial.

Cell death and conductivity assay of $P$. noxius. Fungichromin is an antibiotic compound and has been known to play an important role in the growth inhibition of other pathogens by S. padanus PMS-702 (Shih et al. 2003). Therefore, the effect of fungichromin on the viability of the BRR pathogen PB01 was of interest. Fungichromin was produced and purified from $S$. padanus PMS-702 by a local company (Sinon Co.). To investigate the effect of fungichromin on $P$. noxius, an agar block (6 $\mathrm{mm}$ in diameter) cut from a $P$. noxius PB01 colony edge was transferred to the center of a fresh PDA plate. Four cover slips were placed equally in four directions $1 \mathrm{~cm}$ away from the agar block. After the hyphae had grown over the cover slips, $100 \mu$ l of fungichromin $(0,5,10$, or $20 \mathrm{ppm}$; Sinon Co., Taiwan) was applied to the cover slip. At $12 \mathrm{~h}$ postincubation with fungichromin, residual water was removed from the cover slips, and $20 \mu \mathrm{l}$ of reagent from a Bacterial Viability Kit (LIVE/DEAD BacLight, Thermo Fisher Scientific) was applied. The PDA plates were placed in the dark for an additional $10 \mathrm{~min}$, and then the coverslips were carefully removed and examined under a fluorescence microscope. With excitation/emission wavelengths of $480 / 500 \mathrm{~nm}$ for SYTO 9 and $490 / 635 \mathrm{~nm}$ for propidium iodide, live (green fluorescent) and dead (red fluorescent) cells were distinguished.

To determine the median effective dose $\left(\mathrm{ED}_{50}\right)$ of fungichromin for BRR pathogens, a mycelium plug of PB01 or TC10 was inoculated onto the center of PDA medium containing different
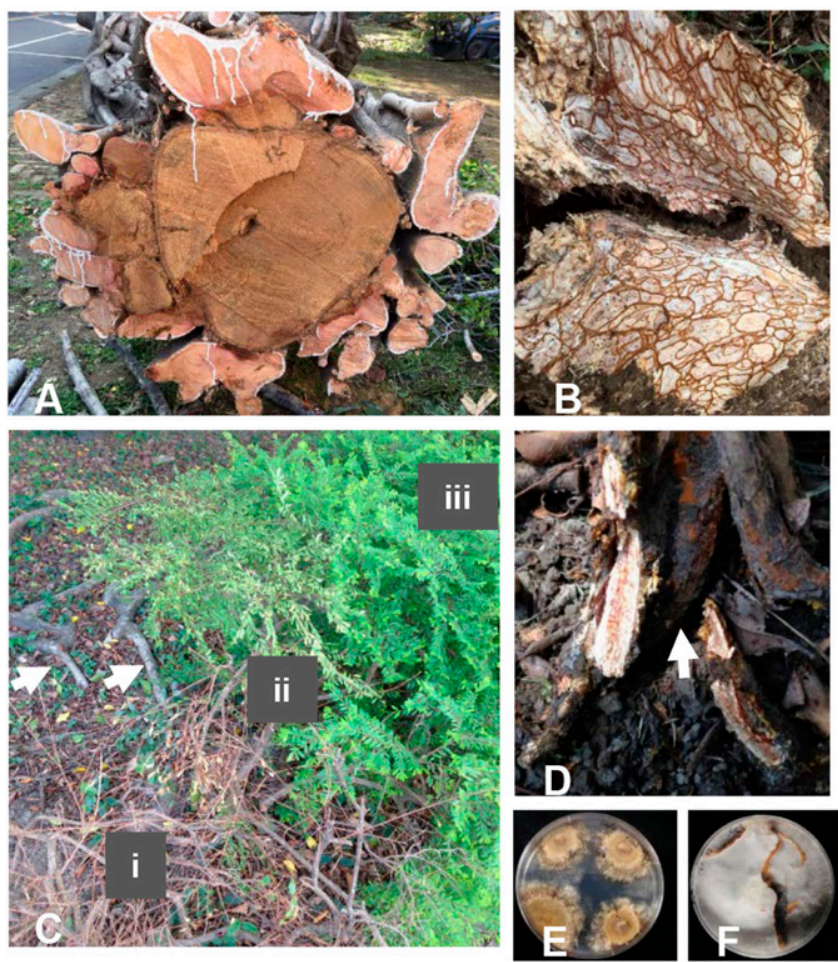

Fig. 1. Brown root rot disease symptoms of Ficus microcarpa (Chinese banyan) (A and B) and Phyllanthus myrtifolius (Ceylon myrtles) (C and D) and pathogen phenotypes $(\mathbf{E}$ and $\mathbf{F})$. Cross section of the infected Chinese banyan $(A)$ and typical zone lines and network patterns under the bark of the trunk $(B)$ are presented. Through root-toroot connections, pathogens spread from the roots of Chinese banyan (indicated with arrows) to Ceylon myrtles, and Ceylon myrtles were infected one by one. The first diseased Ceylon myrtle plant (i) was dead, the second plant (ii) was chlorotic, and the third plant (iii) remained heathy (C). Root decay and dark brown mycelial mats (indicated with an arrow) were observed on the roots of the diseased Ceylon myrtle plants (D). The pathogen was isolated from the roots of the plant (i) and grown on semiselective medium (E), and a typical irregular dark brown zone line formed on a PDA plate $(\mathbf{F})$. concentrations of fungichromin $(0,1,2,5,10$, or $20 \mathrm{ppm})$. After 4 days of incubation at $28^{\circ} \mathrm{C}$, the radial growth (diameter) was measured daily, and the growth inhibition rate was used to calculate the $\mathrm{ED}_{50}$ by the creation of trend lines in Excel (Microsoft Office).

A conductivity assay for cytoplasmic leakage of mycelial cells was performed. Mycelia of $P$. noxius $\mathrm{PB} 01$ cultured in potato dextrose broth (Difco) for 5 days were harvested, rinsed with sterile Milli-Q water, and placed in a $250-\mathrm{ml}$ flask (10 g mycelia/flask) containing $100 \mathrm{ml}$ of sterile Milli-Q water or $10 \mathrm{ppm}$ of fungichromin. A flask containing $100 \mathrm{ml}$ of $10-\mathrm{ppm}$ fungichromin without the presence of mycelium served as a control. The conductivity of each treatment was measured at 3, 6, 9, and $12 \mathrm{~h}$ after incubation.

Data analysis. Experiments were performed at least twice with at least three replicates of each treatment within each experiment, except as indicated otherwise. The significance of differences was determined by $t$ test or Tukey's HSD test at $P<0.05$ using Statistical Package for the Social Sciences software, version 20 (IBM SPSS software).

\section{Results}

Characterization of BRR pathogens isolated in this study. Ceylon myrtles under the shade of BRR-infected Chinese banyans on the campus of NCHU in Taichung, Taiwan, have shown wilting symptoms since 2017 (Fig. 1). The BRR wilting symptoms appeared progressively on adjacent Ceylon myrtles. Leaf blight and root decay as
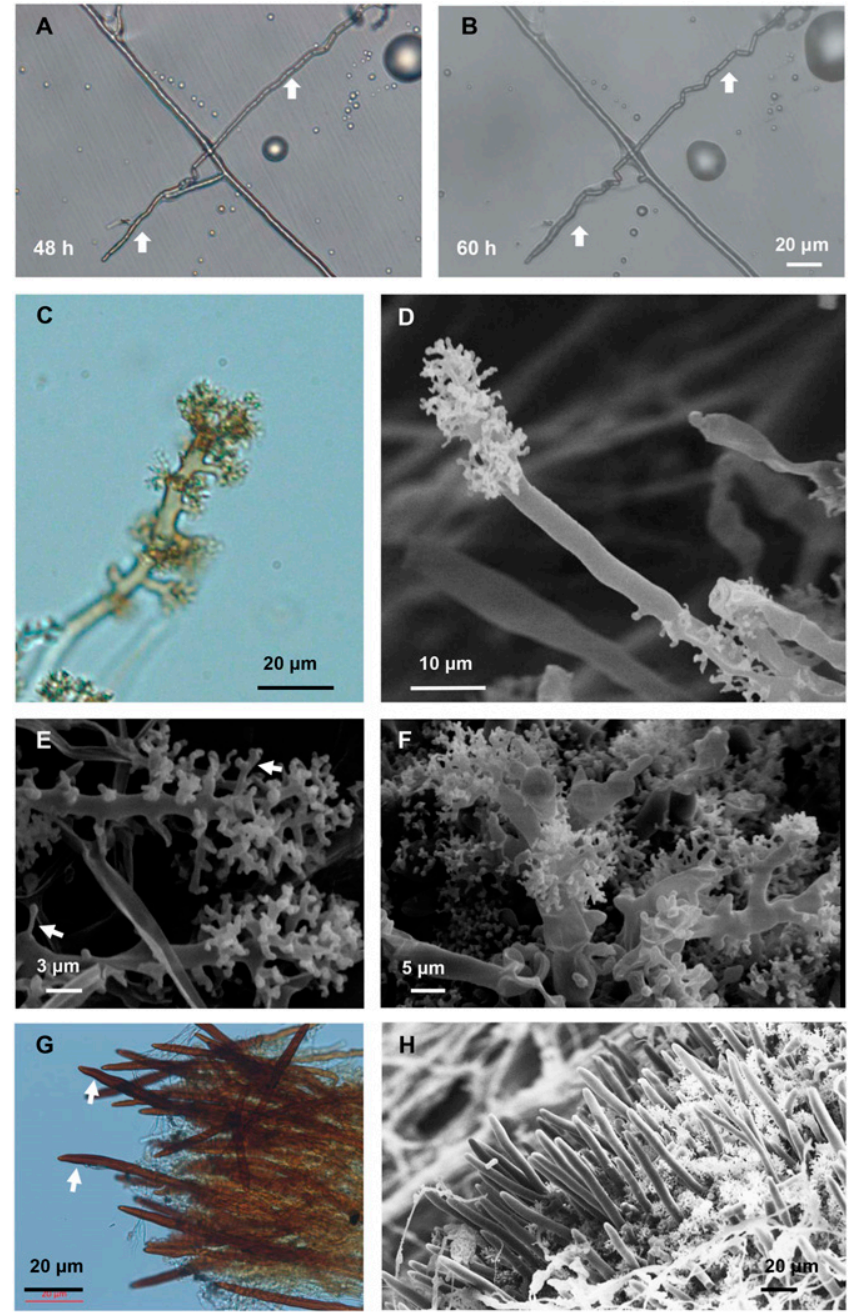

Fig. 2. Morphology of Phellinus noxius PB01 isolated from infected Ceylon myrtle examined by light microscopy (A, B, C, and G) and scanning electron microscopy $(\mathrm{D}, \mathrm{E}, \mathrm{F}$, and H). Arthrospore formation at $48 \mathrm{~h}(\mathrm{~A})$ and $60 \mathrm{~h}(\mathrm{~B})$. Trichocyst formation on PDA at 12 dpi (C, D, E, and F). Setal hyphae formed on the fruiting body after 2 months of in vitro cultivation ( $\mathbf{G}$ and $\mathbf{H}$ ). 
well as brown mycelial mats on the stem bases were observed on infected Ceylon myrtles (Fig. 1). Because this is the first report of BRR on Ceylon myrtle, an isolate from Ceylon myrtle, PB01, was used for the examination of the microscopic features of the pathogen, including arthrospores, trichocysts, and setal hyphae (Fig. 2). Arthrospores and trichocysts are commonly produced by P. noxius in culture (Ann et al. 2002; Chung et al. 2015), and hymenial setae and the production of setal hyphae in the fruiting body are features that distinguish $P$. noxius from the closely related species $P$. lamaensis (Holliday 1995). During routine cultivation of BRR pathogens, we found that arthrospores always formed on the surface of the Petri dish lid when the hyphae grew up and reached the lid surface. Therefore, by placing

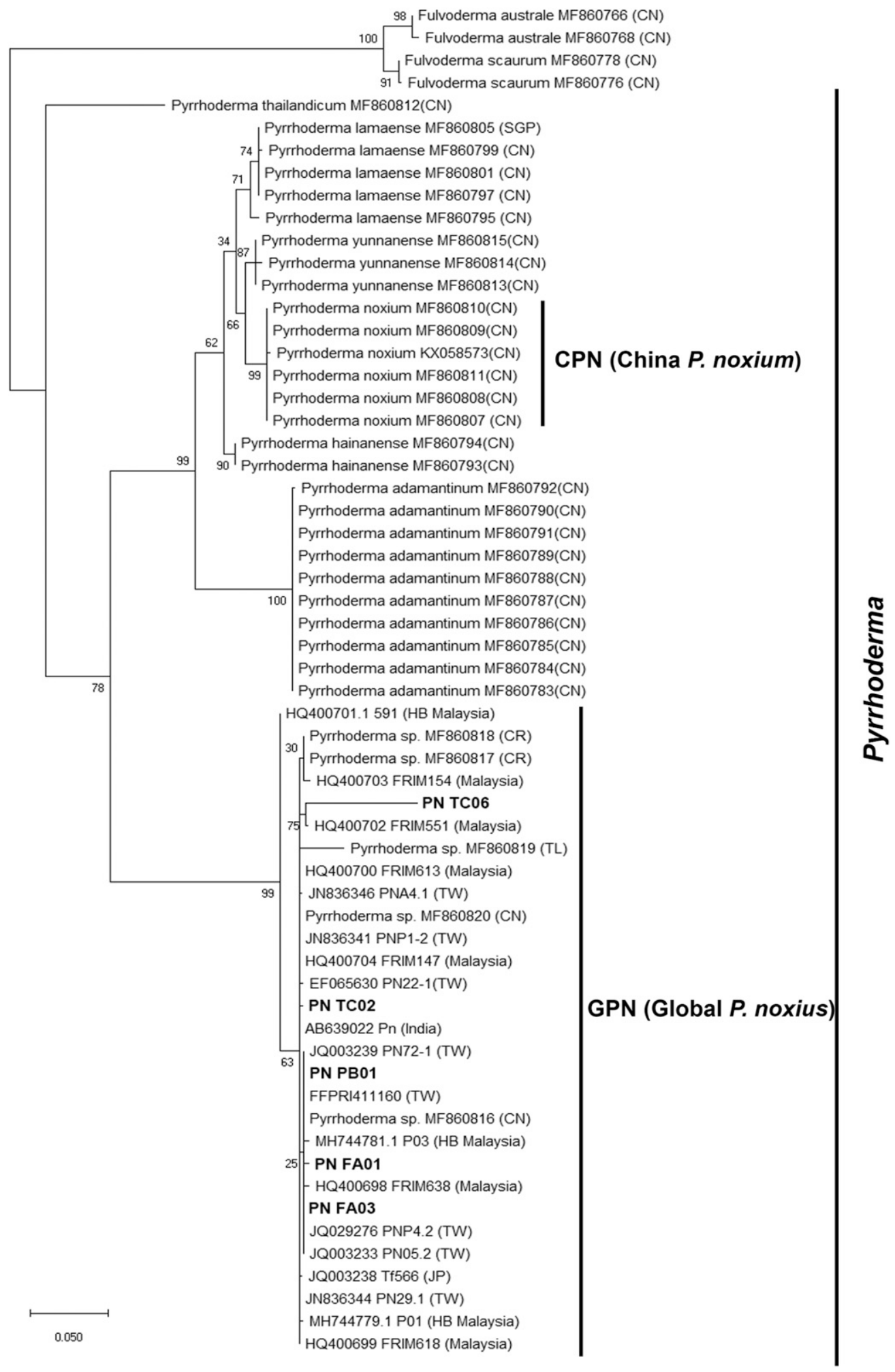

Fig. 3. Molecular phylogenetic analysis of Phellinus noxius isolates using ITS sequences by the maximum likelihood method. Twenty-four isolates of Phellinus and 32 isolates of Pyrrhoderma were used in this analysis, and Fulvoderma spp. were used as an outgroup to root the tree. Branch lengths and bootstraps (1,000 replicates) obtained with neighborjoining and bootstrap methods are displayed on the tree. The isolates (PN TC06, PN TC02, PN PB01, PN FA01, and PN FA03) identified in this study are indicated in bold. CPN = China Pyrrhoderma noxium, and GPN = global Phellinus noxius. 
a mycelial agar plug on an empty Petri dish in a moisture chamber, hyaline and rod-shaped arthrospores could be produced on the Petri dish surface at $48 \mathrm{~h}$ postincubation (Fig. 2A and B). Dark brown trichocysts were observed in aged cultures, usually when the culture turned brown and the surface became brown and fluffy (Fig. 1E). The microscopic structure of trichocysts was examined by light microscopy and SEM (Fig. 2C to F). The diameters of the tiny branches were between approximately 0.6 and $1.0 \mu \mathrm{m}$ (Fig. 2E, indicated with arrows). The morphology was similar to that of dendrohyphidium described previously (Nicole et al. 1995). The tiny and multiplebranched hyphae of trichocysts largely increased the surface area of this fungus (Fig. 2F). Hymenial setae were not observed, but radially arranged unbranched setal hyphae were observed on the fruiting body surface (Fig. 2G and H). Setal hyphae had thick walls and a

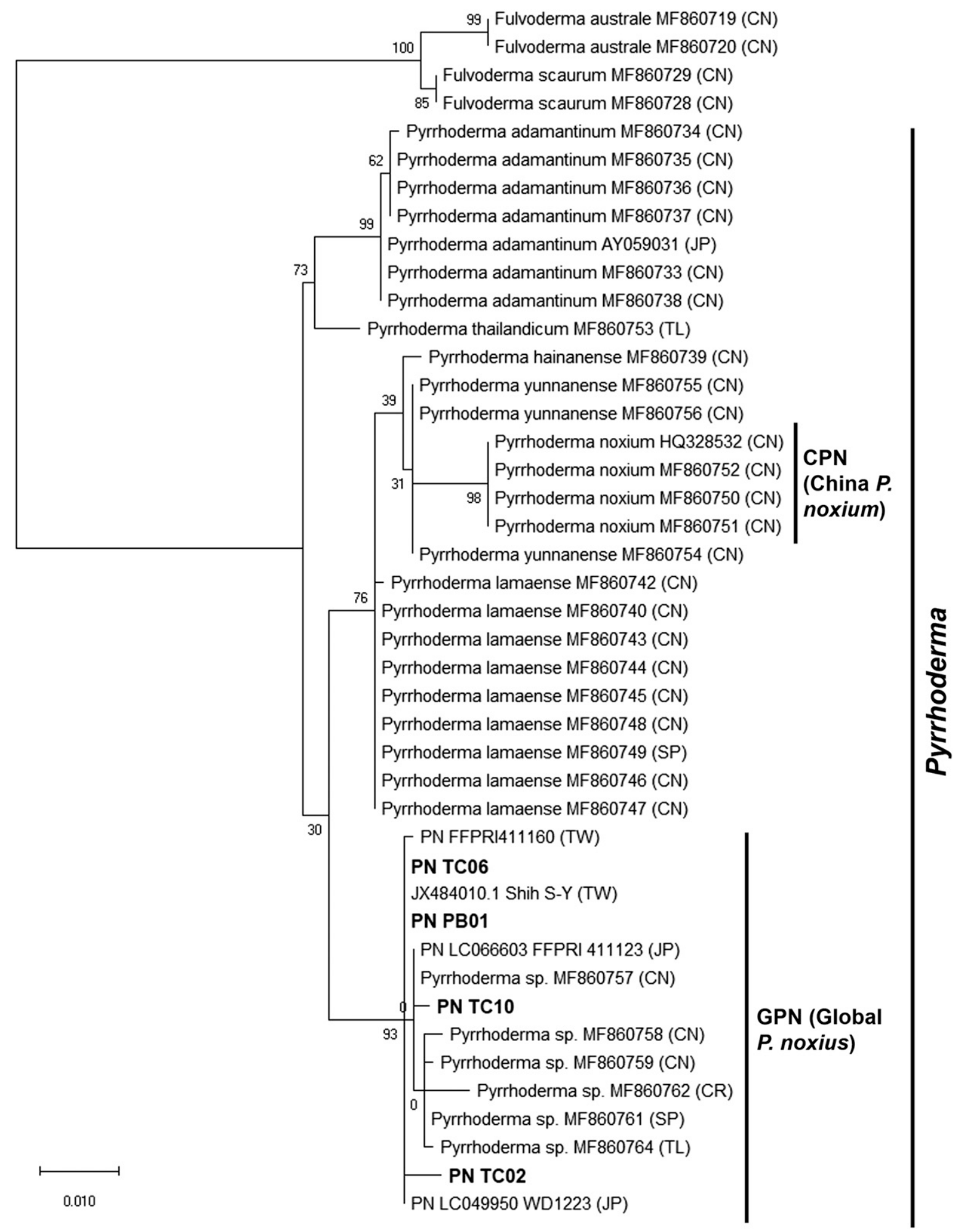

Fig. 4. Molecular phylogenetic analysis of Phellinus noxius isolates using $28 \mathrm{~S}$ sequences by the maximum likelihood method. Eight isolates of Phellinus and 31 isolates of Pyrrhoderma were used in this analysis, and Fulvoderma spp. were used as an outgroup to root the tree. Branch lengths and bootstraps (1,000 replicates) obtained with neighbor-joining and bootstrap methods are displayed on the tree. The isolates (PN TC06, PN PB01, PN TC10, and PN TC02) identified in this study are indicated in bold. $\mathrm{CPN}=$ China Pyrrhoderma noxium, and GPN = global Phellinus noxius. 
dark chestnut brown color (Fig. 2G, indicated with arrows). The diameter of the setal hyphae was approximately $6.76 \mu \mathrm{m}$.

Alignment and phylogenetic relationships of the BRR pathogens. In this study, a total of six $P$. noxius isolates were isolated from six individually infected trees of three different hosts, including Ficus microcarpa, Melia azedarach, and Phyllanthus myrtifolius (Table 1). All six isolates formed a typical irregular dark brown zone line when cultured on PDA for approximately 4 to 6 days, as shown in Figure 1F. The ITS and 28S sequences of the six isolates obtained in this study were used in the phylogenetic analyses with 55 ITS sequences and 3928 S sequences, which were described by Tsai et al. (2017), Chung et al. (2017), and Zhou et al. (2018) (Supplementary Table S1). Phylogenetic analysis based on 60 ITS sequences resulted in a total of 562 positions in the final dataset. The data showed that species of Fulvoderma were separated from the others (100\%). All 13 Taiwan BRR isolates, including five isolates from this study, and 16 other isolates identified as $P$. noxius from various locations constituted a distinct clade (Fig. 3) separate from the clade comprising the six isolates described as Py. noxium by Zhou et al. (2018). The 28S dataset included 43 nucleotide sequences that displayed a total of 870 positions. In the phylogenetic tree (Fig. 4) based on the 28S dataset, isolates from Taiwan were also separated into different clades from the isolates from China. Phylogenetic analysis based on the ITS sequence revealed that three pathogens (FA01, FA03, and PB01) isolated from different trees planted at the same location at NCHU were closely related (Fig. 3). ITS sequence alignment of the three isolates showed highly conserved sequences among them compared with TC02, which was isolated from outside of the NCHU campus (Supplementary Fig. S2).
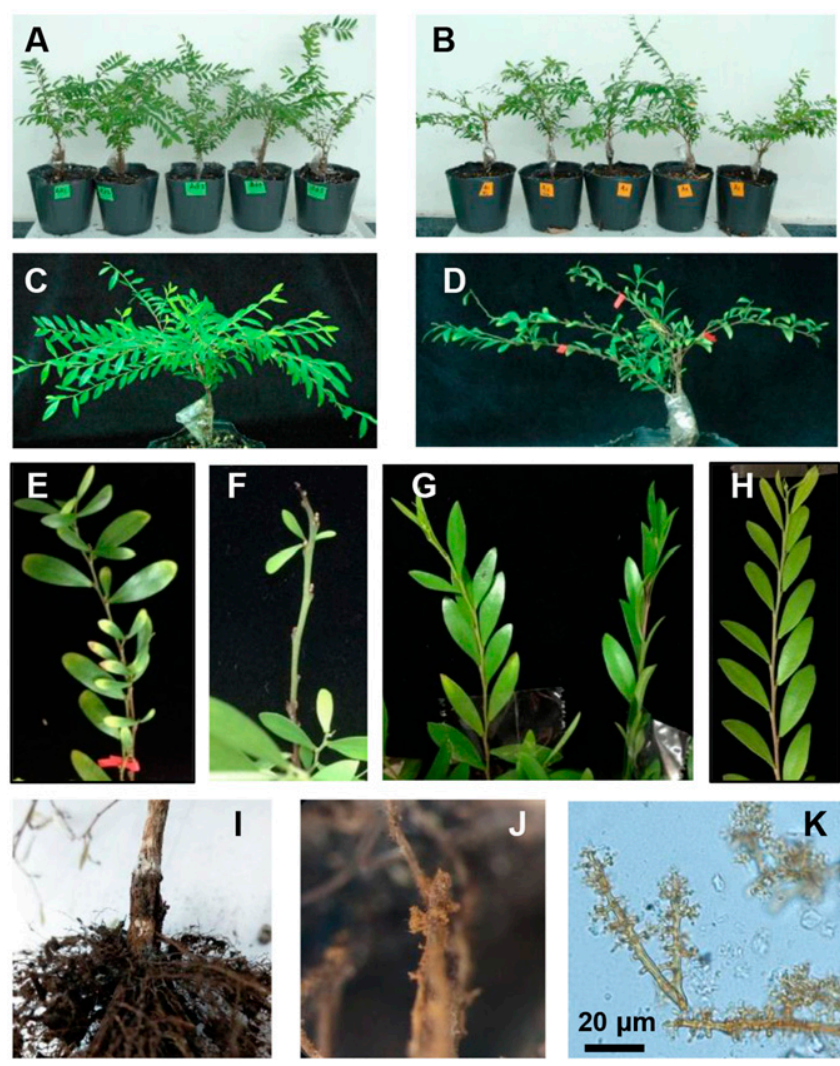

Fig. 5. Symptoms of Ceylon myrtle seedlings infected with Phellinus noxius PB01 at 8 weeks postinoculation. Control seedlings $(\mathbf{A})$ remained symptomless. Defoliation and decline symptoms were present on infected seedlings (B). The canopies of control (C) and infected (D) seedlings were enlarged to see the differences. The main symptoms included leaf size reduction $(\mathbf{E})$, dieback of branches $(\mathbf{F})$, and physical malfunctions $(\mathbf{G}$; left: unclosed leaflets, right: closed leaflets). The leaves of the control seedlings are presented $(\mathbf{H})$. Bases of stems of the seedlings covered with a dark brown mycelial crust (I) and trichocysts ( $\mathbf{J}$ and $\mathbf{K})$.
Disease progress and disease severity of BRR on Ceylon myrtle. Inoculation of wounded roots with sawdust spawn or wounded stem bases with grain spawn was evaluated. Wound inoculation on the stem base resulted in stable and severe disease symptoms (data not shown). Therefore, experiments with stem base wound inoculation were performed to examine BRR symptom development in Ceylon myrtle. The seedlings exhibited a slow decline, including leaf yellowing and partial defoliation, within 1 month postinoculation with $P$. noxius isolate PB01 compared with the control treatment (Fig. 5A to D). Leaves of the new growth appeared smaller and thinner than the uninoculated leaves and were arranged on twigs in a disordered fashion (Fig. 5E). Two months postinoculation, the inoculated plants displayed severe defoliation, leaf size reduction and chlorosis, branch dieback, and malfunction as young leaves remained unclosed at night (Fig. 5F and G). The stem bases of the seedlings were covered with a dark brown mycelial crust and trichocysts at 2 months postinoculation (Fig. 5I to K). The pathogen was reisolated from infected roots and confirmed as $P$. noxius by colony morphology and fungal structures as well as PCR amplification using the $P$. noxius-specific primer pair G1F and G1R (Wu et al. 2009). Although seedlings declined gradually, the seedlings still survived 4 months after inoculation.

Based on the symptom appearance and disease progress, a disease index was used to evaluate the disease severity as shown in Figure 6. A disease severity index of 0.21 was recorded for the seedlings at 2 months postinoculation (mpi), and this value increased to 0.32 at 4 mpi (Fig. 6). The disease severity progressively increased, and

\begin{tabular}{|c|c|c|c|}
\hline Level & Canopy loss & Symptom & Phenotype \\
\hline 0 & 0 & None & \\
\hline 1 & $<20 \%$ & Defoliation, chlorosis & \\
\hline 2 & $20-40 \%$ & $\begin{array}{l}\text { Leaf area reduction, } \\
\text { decline, defoliation }\end{array}$ & \\
\hline 3 & $40-75 \%$ & Dieback, defoliation & \\
\hline 4 & $>75 \%$ & $\begin{array}{c}\text { Dieback, serious } \\
\text { defoliation }\end{array}$ & \\
\hline 5 & & ead plant & \\
\hline
\end{tabular}

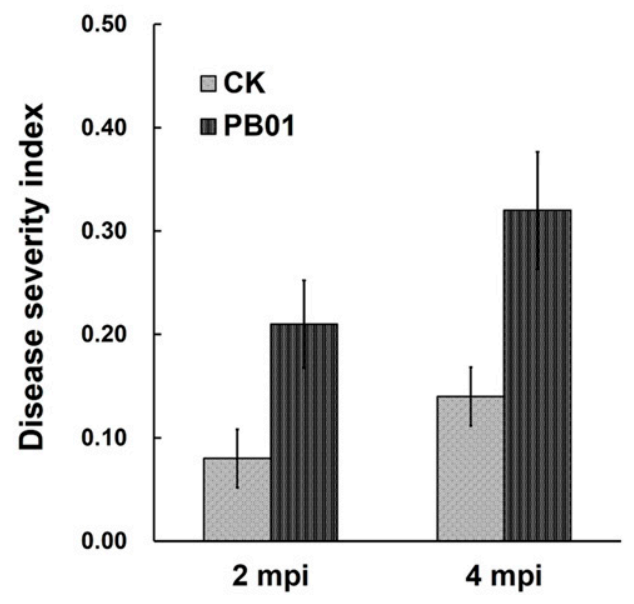

Fig. 6. Upper panel: disease index (level 0 to 5) used to determine disease severity. Lower panel: disease severity index of seedlings of Ceylon myrtle 2 and 4 months postinoculation (mpi) with wheat inoculum of brown root rot isolate PB01 or sterile water (CK) on the wounded stem base. 
symptoms of decline gradually became more obvious after inoculation.

Susceptibility of Ceylon myrtle to BRR pathogens. Malabar chestnut was previously reported to be susceptible to BRR (Ann et al. 1999b). Therefore, Malabar chestnut seedlings generated by cutting propagation were used as a parallel treatment to evaluate the susceptibility of Ceylon myrtle to the BRR pathogen. The results showed that seedlings of Malabar chestnut treated with the pathogen (TC10) were dead, showing $100 \%$ morality, within 2 weeks postinoculation. However, seedlings of Ceylon myrtle treated with the pathogen exhibited disease symptoms at $1 \mathrm{mpi}$ and remained alive for up to 6 months. To investigate the tolerance of Ceylon myrtle to BRR pathogens, Ceylon myrtle seedlings were inoculated with isolates PB01, FA01, and TC10 and incubated for a long period. One year postinoculation, the disease severity of seedlings inoculated with isolates FA01, PB01, and TC10 was $0.7,0.65$, and 0.65 , respectively, and only one or two seedlings were killed among the four inoculated seedlings (Supplementary Fig. S3). The results indicated that Ceylon myrtle is relatively tolerant to BRR disease compared with Malabar chestnut.

Disease control of BRR on Ceylon myrtle with two bacterial antagonists in greenhouse trials. Three bacterial isolates exhibiting over 50\% growth inhibition to isolates TC10 and PB01 were found (Fig. 7). Strain BB118 was identified by 16S rRNA gene sequence analysis. The best hit in the EzBioCloud 16S database was Bacillus siamensis (AJVF01000043), with 99.93\% similarity and 1/1,441 Diff/total nt. The best hit resulting from NCBI BLAST analysis was Bacillus velezensis (CP046386.1) with $100 \%$ coverage $(1,450$ nt) and $99.79 \%$ identity. JW7 was identified as a Burkholderia sp. by $16 \mathrm{~S}$ rRNA gene sequence analysis (data not shown). Compared with BB118 and PMS-702, JW7 displayed less antagonistic activity and slow growth in the dual culture plate (Fig. 7). Therefore, it was not used to evaluate disease control ability in an in planta assay. The antagonists S. padanus PMS-702 and Bacillus sp. BB118, which displayed mycelium growth inhibition rates of PB01 of up to 81 and $72 \%$, respectively, were used to evaluate the control efficacy of Ceylon myrtle BRR in a greenhouse. All fresh cuttings were treated with

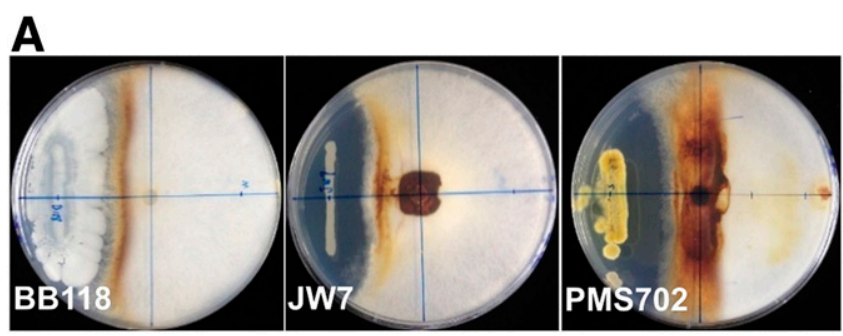

B

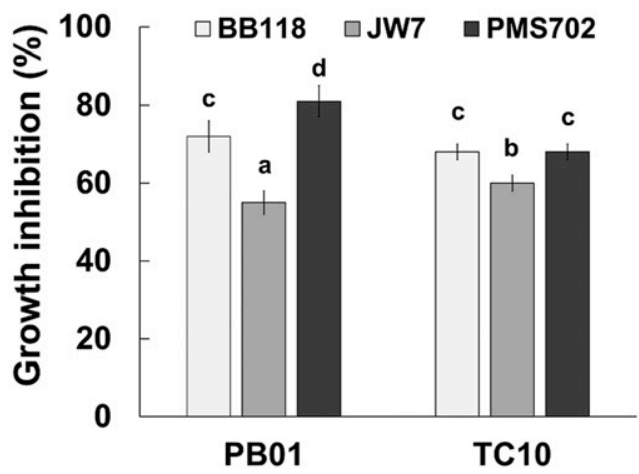

Fig. 7. Antagonism assays of Streptomyces padanus PMS-702 (PMS702), Bacillus sp. BB118, and Burkholderia sp. JW7 against Phellinus noxius isolate PB01 (A) and isolates PB01 and TC10 (B). The antagonistic activity determined from dual culture (A) and growth inhibition assays (B) is presented. Means of each property followed by the same letter are not significantly different. the pathogen and/or the antagonist and thereafter cultivated for 2 months. The seedlings were collected for phenotypic evaluation based on the growth index and disease index (Fig. 8A), in which the phenotype of the root system was included. The disease severity was measured, and the averages of two independent greenhouse trials were presented (Fig. 8B). The culture broths of S. padanus PMS-702 and Bacillus sp. BB118 could reduce disease severity from 0.51 to 0.37 and 0.14 , respectively, at a 50-fold dilution. Bacillus sp. BB118 showed highly significant BRR disease control abilities, reaching the same level as the healthy control treatment. In pathogen-free treatments, root and shoot formation of the fresh cuttings was promoted by the two biocontrol agents, especially when the culture broths were adjusted to a 50-fold dilution (Fig. 8C). S. padanus PMS-702 application was shown to have better and more stable growth promotion abilities than Bacillus sp. BB118. In the two trials, a 50-fold dilution of $S$. padanus PMS-702 culture broth significantly promoted seedling growth. The average seedling growth index of the two trials increased significantly from 0.56 to 0.89 , with $P<0.5$. Both biocontrol agents exhibited a slightly better growth-promoting effect than the commercial rooting stimulator 2-

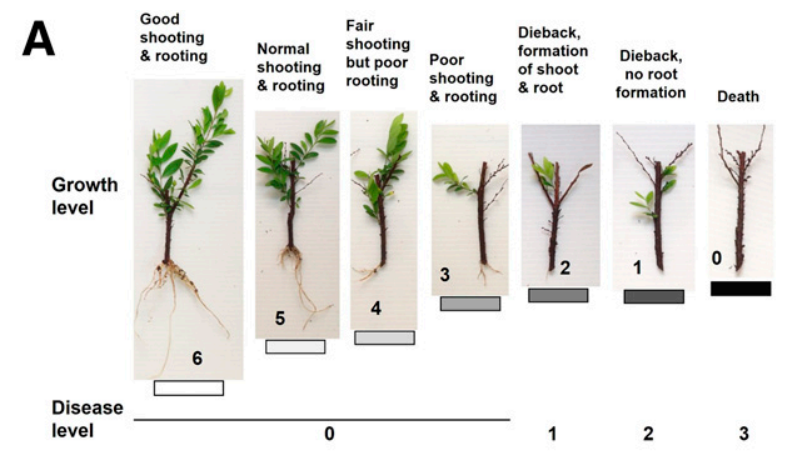

B
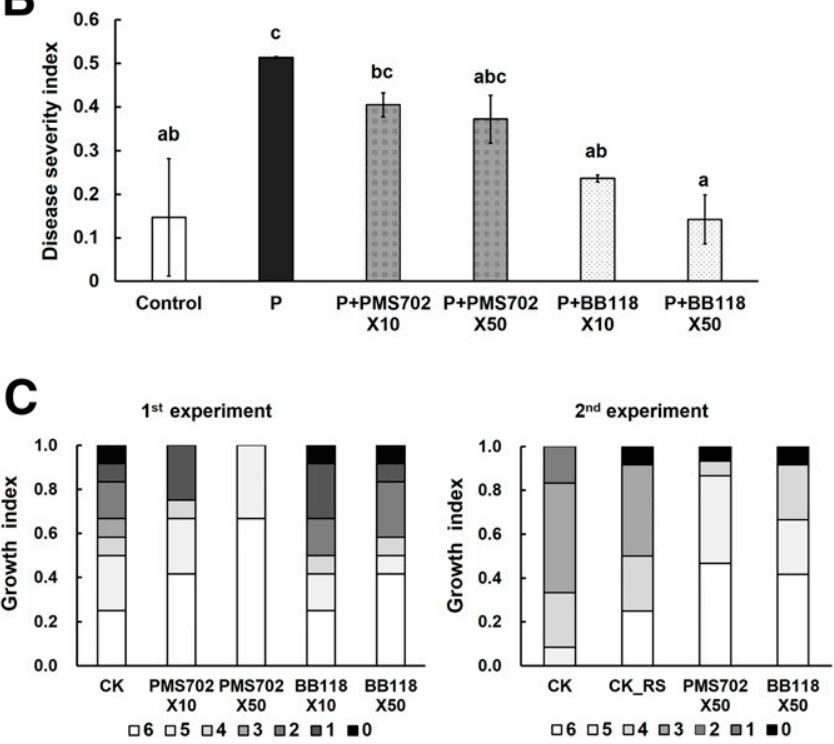

Fig. 8. Disease control ( $A$ and $B$ ) and growth promotion ( $A$ and $C$ ) of Ceylon myrtle by the application of culture broth of the biocontrol agents Streptomyces padanus PMS702 (PMS702) and Bacillus sp. BB118 at 8 weeks postincubation. A, Growth levels and disease levels were used to evaluate growth promotion and disease control. B, Disease severity of plantlets after propagation of cuttings on substrates inoculated with Phellinus noxius PB01 and treated with biocontrol agents. The value represented means of two independent greenhouse trials. Means of each property followed by the same letter are not significantly different. $\mathbf{C}$, The growth of the plantlets after treatment with biocontrol agents PMS702 and BB118, root stimulator (CK_RS), and water (CK). The data are presented as the percentage of seven growth levels shown in panel $\mathrm{A}$ for each treatment. $\mathrm{P}=$ pathogen; $\mathrm{X} 10=10$-fold dilution; and $\mathrm{X} 50=50$-fold dilution . 
(1-naphthyl) acetamide (CK_RS, Fig. 8C) in the second greenhouse trial.

The effect of fungichromin on the viability of BRR pathogens. A viability indicator (LIVE/DEAD BacLight) was used to examine live and dead cells. Under a fluorescence microscope, orange and green colors of the cells were present (Supplementary Fig. S4A). Green represented healthy cells, and orange represented injured or dead cells. In the control treatment, hyphae displayed only a green color. Orange color appeared in both hyphae and arthrospores when treated with $5 \mathrm{ppm}$ of fungichromin, and only a few hyphae remained green when treated with $10 \mathrm{ppm}$ of fungichromin. All fungal cells were killed when treated with $20 \mathrm{ppm}$ of fungichromin. In the $\mathrm{ED}_{50}$ determination, with the increase in fungichromin concentration, the growth diameter of the BRR pathogen decreased (Supplementary Fig. S4B). The $\mathrm{ED}_{50}$ values of fungichromin for the BRR pathogens PB01 and TC10 were 2.7 and $3.1 \mathrm{ppm}$, respectively, after treatment for 4 days.

Conductivity assays indicated that cytoplasmic leakage increased significantly when mycelium and fungichromin were combined together in water (Supplementary Fig. S4C). Especially in the first $3 \mathrm{~h}$, conductivity increased from 25 to $41 \mu \mathrm{s} / \mathrm{cm}$ and reached $48 \mu \mathrm{s} / \mathrm{cm}$ at $12 \mathrm{~h}$. With water and mycelium, conductivity slightly increased and reached a peak at $28 \mu \mathrm{s} / \mathrm{cm}$ at $6 \mathrm{~h}$. With water and fungichromin, the conductivity remained at $14 \mu \mathrm{s} / \mathrm{cm}$.

\section{Discussion}

BRR is becoming the most destructive tree disease in Taiwan (Chung et al. 2015; Tsai et al. 2017). New infections have been reported frequently, and various disease control strategies have been developed, but promising and environmentally friendly methods are in high demand. In this study, six BRR pathogens were isolated from three tree species, and we report, for the first time, Ceylon myrtle as a host of $P$. noxius. Phylogenetic analysis based on the ITS sequence revealed that three pathogens (FA01, FA03, and PB01) isolated from plants at the same location were closely related (Fig. 3). In addition, out of a total of $647 \mathrm{bp}$ in the ITS sequence, the nucleotide difference between isolates PB01 and TC02 was $12 \mathrm{bp}$, whereas there were no differences between PB01 and isolate FA03 (Supplementary Fig. S2). PB01 was isolated from Ceylon myrtle, whereas FA01 and FA03 were isolated from Chinese banyan, a previously infected tree adjacent to the Ceylon myrtle. In this study, no basidiocarps were observed on any infected plants. The spread of $P$. noxius by basidiospores from Chinese banyan to the newly recorded host Ceylon myrtle is very unlikely because spread generally occurs via root-to-root connections. Several previous studies have suggested that this pathogen might infect nearby plants through root-to-root connections and use basidiospores for long-distance dissemination (Akiba et al. 2015; Chung et al. 2015, 2017). In addition, a recent study revealed that soil is not a reservoir for $P$. noxius ( $\mathrm{Wu}$ et al. 2020). Therefore, the survival and short-distance distribution of $P$. noxius is highly dependent on infected host plant tissues.

Zhou et al. (2018) suggested moving $P$. noxius to the newly proposed genus Pyrrhoderma based on phylogenetic analyses of ITS and $28 \mathrm{~S}$ sequences. However, the sequences used to represent $P$. noxius were not derived from the type material but from materials collected in Hainan, China. Phylogenetic analysis in this study based on ITS or 28S sequences showed that a clade containing Taiwan isolates, which were obtained from BRR and considered to be $P$. noxius, was distinct from the clade containing China isolates, which were attributed to Pyrrhoderma noxium by Zhou et al. (2018). Because there is no type strain of $P$. noxius (Py. noxium) available for analysis, it is uncertain which clade is qualified to represent the scientific name. Consequently, to clarify this situation, the former clade is designated GPN, referring to global $P$. noxius; the latter clade is designated CPN, referring to China Py. noxium. GPN contains isolates from Taiwan, Malaysia, Japan, China, Singapore, Thailand, India, and Costa Rica, whereas isolates in CPN all were isolated from China. Because the GPN clade is sister to the CPN clade, they can both be accommodated in the genus Pyrrhoderma. However, until the taxonomic issues can be resolved, we will refer to the GPN clade containing the BRR pathogen in Taiwan as $P$. noxius throughout the current study.

In addition to molecular analysis, we also demonstrated the formation of arthrospores, trichocysts, and unbranched setal hyphae, which are important fungal structures formed by $P$. noxius according to the description of Holliday (1995) and other studies (Ann et al. 2002). Arthrospore formation was observed on axenic cultures, as recorded previously (Ann et al. 2002). Moreover, we found that arthrospore formation can be induced on the surface of polystyrene Petri dishes, which are hydrophobic and lack nutrients. Arthrospore formation of P. noxius has never been observed in nature (Ann et al. 2002). However, we could not exclude the possibility that arthrospore formation occurs in the field and thus provides inoculum when the infection is at a very late stage under nutrient shortage. Trichocysts are commonly observed on aged cultures and diseased tissues (Ann et al. 1999b). Our SEM data clearly displayed highly branched trichocysts, and the morphological type was highly similar to that of dendrohyphidium (Fig. 18 in Hawksworth et al. 1995). The function of trichocysts in fungi has not been discovered. Because the formation of trichocysts largely increases the fungal surface, these structures might have a role in interacting with the environment. The narrow setal hyphae of PB01 were approximately $6.76 \mu \mathrm{m}$ in size. According to Holliday (1995), setal hypha are an important feature to distinguish $P$. noxius from the closely related species $P$. lamaensis. $P$. lamaensis has hymenium setae and narrow setal hyphae (up to $7 \mu \mathrm{m}$ ), whereas $P$. noxius has no setae but has context setal hyphae (4 to $13 \mu \mathrm{m}$ ) with dark chestnut brown thick walls. Although the setal hyphae diameter could not distinguish the two Phellinus species, we did not observe hymenium setae formation in P. noxius PB01.

$P$. noxius can infect trees and shrubs. Orange jasmine (Murraya paniculata), golden dewdrop (Duranta repens), Chinese hibiscus (Hibiscus rosa-sinensis), and common lantana (Lantana camara) are shrubby hosts of $P$. noxius identified in Taiwan (Ann et al. 1999c). Ceylon myrtle and the shrubs mentioned above are frequently used in urban horticulture as hedge plants. Ceylon myrtle is often planted under tree crowns due to its shade tolerance. To the best of our knowledge, this is the first report of BRR on Ceylon myrtle. Koch's postulates were completed to verify the pathogenicity of the causal agent on Ceylon myrtle. The pathogen reisolated from the root bases of inoculated seedlings was confirmed by colony morphology, and the molecular marker was amplified by PCR using the P. noxius-specific primer pair G1F and G1R (Wu et al. 2009; data not shown). By completing Koch's postulates, we demonstrated that Ceylon myrtle is a new host of $P$. noxius. The infected seedlings showed typical symptoms of BRR, and disease severity continued to increase week after week. However, Ceylon myrtle exhibited strong tolerance to $P$. noxius compared with Malabar chestnut, in which $100 \%$ mortality was observed within 2 weeks postinoculation. Low mortality of Ceylon myrtle was measured 1 year postinoculation. The tolerance of Ceylon myrtle to BRR might be associated with the presence of various lignan compounds in this species (Lee et al. 1996; Wang et al. 2011; Windayani et al. 2015). Lignans have antifungal activity and are important secondary metabolites in the plant defense response (Bagniewska-Zadworna et al. 2014; Cho et al. 2007; Vogt et al. 2013).

For controlling BRR disease, several methods and chemicals have been tested, including chemical and nonchemical treatments (Chang and Chang 1999; Chou et al. 2019; Tsai et al. 2005). To inhibit disease development, chemicals must be applied periodically, but infected and damaged trees cannot be healed effectively. The application of biocontrol agents to the rhizosphere might provide two advantages: growth promotion of plants and protection from pathogens. In this study, S. padanus PMS-702 and Bacillus sp. BB118 were selected to conduct disease control assays due to their good inhibition of $P$. noxius in vitro. The two biocontrol agents showed significantly effective disease control, and Bacillus sp. BB 118 could reduce disease severity up to $50 \%$ with only one application. In addition, the pathogen-inoculated cuttings treated with 50fold diluted BB118 culture broth maintained better health than the uninoculated cuttings. S. padanus PMS-702 showed strong growth 
promotion of cuttings in two independent experiments, especially when cuttings were treated with the 50-fold diluted culture broth (Fig. 8). However, this effect was not observed in pathogen-treated seedlings. S. padanus PMS-702 presented better inhibition of the growth of $P$. noxius on PDA but less of a protective effect on cuttings of Ceylon myrtle than Bacillus sp. BB118. Two factors might be involved in the disease control efficacy of PMS-702. First, Streptomyces can solubilize phosphate, various enzymes, plant growthpromoting enzymes, and auxins when it enters roots and colonizes root tissues and vessels (Vurukonda et al. 2018). However, plant root exudates (such as flavonoids, strigolactones, and terpenoids) are needed to attract Streptomyces to shape the microbial communities in the rhizosphere (Vurukonda et al. 2018). In this study, P. noxius-treated cuttings were rootless at first. Therefore, the communities of S. padanus PMS-702 were unable to form, and no further colonization was developed due to the lack of a typical rhizosphere community. Second, the in situ availability of antimicrobial compounds produced by $S$. padanus PMS-702-like fungichromin needs to be considered (Shih et al. 2003). Fungichromin was demonstrated in this study to cause membrane damage and cell death of $P$. noxius, indicating that fungichromin contributes to the antimicrobial effect of PMS-702 against $P$. noxius. In the soil environment, antimicrobial compounds could be diluted or degraded to a low level that reduced the inhibition of pathogens. Similar to $S$. padanus PMS-702, Bacillus sp. BB118 may produce antibiotics such as cyclic lipopeptides surfactin, iturin, and fengycin and other beneficial secondary metabolites in the rhizosphere (Fan et al. 2018). Many studies have shown that Bacillus triggers the induced systemic resistance (ISR) of plants to defend against pathogen invasion (Chowdhury et al. 2015; Kloepper et al. 2004); thus, the significant reduction in disease severity of $P$. noxius-treated seedlings by Bacillus sp. BB118 may be in part due to the occurrence of ISR. Although its growth promotion effect was less than that of $S$. padanus PMS-702, Bacillus sp. BB118 exhibited stable and strong disease control of BRR caused by $P$. noxius. Our study indicates that the two biocontrol agents are promising for development as bioprotectants and growth stimulators in nurseries using cutting propagation. In the future, we will expand the use of the two biocontrol agents in tree nurseries and establish an integrated BRR disease management method.

\section{Acknowledgments}

We thank Dr. Jyh-Nong Tsai, Plant Pathology Division of Taiwan Agricultural Research Institute, for technical advice and support on Phellinus noxius culturing for fruiting body production.

\section{Literature Cited}

Akiba, M., Ota, Y., Tsai, I. J., Hattori, T., Sahashi, N., and Kikuchi, T. 2015. Genetic differentiation and spatial structure of Phellinus noxius, the causal agent of brown root rot of woody plants in Japan. PLoS One 10:e0141792.

Ann, P. J., Chang, T. T., and Ko, W. H. 2002. Phellinus noxius brown root rot of fruit and ornamental trees in Taiwan. Plant Dis. 86:820-826.

Ann, P. J., and Ko, W. H. 1992. Decline of longan trees: Association with brown root rot caused by Phellinus noxius. Plant Pathol. Bull. 1:19-25.

Ann, P. J., Lee, H. L., and Huang, T. C. 1999a. Brown root rot of 10 species of fruit trees caused by Phellinus noxius in Taiwan. Plant Dis. 83:746-750.

Ann, P. J., Lee, H. L., and Tsai, J. N. 1999b. Survey of brown root disease of fruit and ornamental trees caused by Phellinus noxius in Taiwan. Plant Pathol. Bull. 8:51-60.

Ann, P. J., Tsai, J. N., Wang, I. T., and Hsien, M. L. 1999c. Response of fruit trees and ornamental plants to brown root rot disease by artificial inoculation with Phellinus noxius. Plant Pathol. Bull. 8:61-66.

Bagniewska-Zadworna, A., Barakat, A., Łakomy, P., Smoliński, D. J., and Zadworny, M. 2014. Lignin and lignans in plant defence: Insight from expression profiling of cinnamyl alcohol dehydrogenase genes during development and following fungal infection in Populus. Plant Sci. 229:111-121.

Burcham, D. C., Wong, J. Y., Abarrientos, N. V., Ali, M. I. M., Fong, Y. K., and Schwarze, F. W. 2017. In vitro evaluation of antagonism by Trichoderma spp. towards Phellinus noxius associated with rain tree (Samanea saman) and Senegal mahogany (Khaya senegalensis). bioRxiv 151753.

Chang, T. T. 1992. Decline of some forest trees associated with brown root rot caused by Phellinus noxius. Plant Pathol. Bull. 1:90-95.

Chang, T. T. 1995. Decline of nine tree species associated with brown root rot caused by Phellinus noxius in Taiwan. Plant Dis. 79:962-965.

Chang, T. T. 1996. Survival of Phellinus noxius in soil and in the roots of dead host plants. Phytopathology 86:272-276.
Chang, T. T., and Chang, R. J. 1999. Generation of volatile ammonia from urea fungicidal to Phellinus noxius in infested wood in soil under controlled conditions. Plant Pathol. 48:337-344.

Cho, J. Y., Choi, G. J., Son, S. W., Jang, K. S., Lim, H. K., Lee, S. O., Sung, N. D., Cho, K. Y., and Kim, J. C. 2007. Isolation and antifungal activity of lignans from Myristica fragrans against various plant pathogenic fungi. Pest Manag. Sci. 63:935-940

Chou, H., Xiao, Y. T., Tsai, J. N., Li, T. T., Wu, H. Y., Liu, L. D., Tzeng, D. S., and Chung, C. L. 2019. In vitro and in planta evaluation of Trichoderma asperellum TA as a biocontrol agent against Phellinus noxius, the cause of brown root rot disease of trees. Plant Dis. 103:2733-2741.

Chowdhury, S. P., Hartmann, A., Gao, X., and Borriss, R. 2015. Biocontrol mechanism by root-associated Bacillus amyloliquefaciens FZB42-A review. Front. Microbiol. 6:780.

Chung, C. L., Huang, S. Y., Huang, Y. C., Tzean, S. S., Ann, P. J., Tsai, J. N., Yang, C. C., Lee, H. H., Huang, T. W., Huang, H. Y., Chang, T. T., Lee, H. L., and Liou, R. F. 2015. The genetic structure of Phellinus noxius and dissemination pattern of brown root rot disease in Taiwan. PLoS One 10: e0139445.

Chung, C. L., Lee, T. J., Akiba, M., Lee, H. H., Kuo, T. H., Liu, D., Ke, H. M., Yokoi, T., Roa, M. B., Lu, M. Y. J., Chang, Y. Y., Ann, P. J., Tsai, J. N., Chen, C. Y., Tzean, S. S., Ota, Y., Hattori, T., Sahashi, N., Liou, R. F., Kikuchi, T., and Tsai, I. J. 2017. Comparative and population genomic landscape of Phellinus noxius: A hypervariable fungus causing root rot in trees. Mol. Ecol. 26:6301-6316.

Corner, E. J. H. 1932. The identification of the brown rot fungus. Gard. Bull. Straits Settl. 5:317-350.

Fan, B., Wang, C., Song, X., Ding, X., Wu, L., Wu, H., Gao, X., and Borriss, R. 2018. Bacillus velezensis FZB42 in 2018: The gram-positive model strain for plant growth promotion and biocontrol. Front. Microbiol. 9:2491.

Forestry Bureau, COA. 2013. Diagnosis and Management of Brown Root Rot Disease. Forestry Bureau, Council of Agriculture, Executive Yuan, Taipei City, Taiwan

Fu, C. H., Hu, B. Y., Chang, T. T., Hsueh, K. L., and Hsu, W. T. 2012. Evaluation of dazomet as fumigant for the control of brown root rot disease. Pest Manag. Sci. 68:959-962.

Hattori, T., Abe, Y., and Usugi, T. 1996. Distribution of clones of Phellinus noxius in a windbreak on Ishigaki Island. Eur. J. Forest Pathol. 26:69-80.

Hawksworth, D. L., Kirk, P. M., Sutton, B. C., and Pegler, D. N. 1995. Ainsworth and Bisby's Dictionary of the Fungi. 8. CAB International, Oxon, U.K.

Holliday, P. 1995. Fungus Diseases of Tropical Crops. Dover Publications, New York, NY.

Huang, H., Sun, L., Bi, K., Zhong, G., and Hu, M. 2016. The effect of phenazine-1carboxylic acid on the morphological, physiological, and molecular characteristics of Phellinus noxius. Molecules 21:613.

Huang, J. W., Shih, H. D., Huang, H. C., and Chung, W. C. 2007. Effects of nutrients on production of fungichromin by Streptomyces padanus PMS-702 and efficacy of control of Phytophthora infestans. Can. J. Plant Pathol. 29: 261-267.

Kloepper, J. W., Ryu, C. M., and Zhang, S. 2004. Induced systemic resistance and promotion of plant growth by Bacillus spp. Phytopathology 94: 1259-1266.

Kumar, S., Stecher, G., Li, M., Knyaz, C., and Tamura, K. 2018. MEGA X: Molecular Evolutionary Genetics Analysis across computing platforms. Mol. Biol. Evol. 35:1547-1549.

Lane, D. J. 1991. 16S/23S rRNA sequencing. Pages 115-175 in: Nucleic Acid Techniques in Bacterial Systematics. E. Stackebrandt and M. Goodfellow, eds. Wiley, Chichester, U.K.

Lee, S. S., Lin, M. T., Liu, C. L., Lin, Y. Y., and Chen Liu, C. S. 1996. Six lignans from Phyllanthus myrtifolius. J. Nat. Prod. 59:1061-1065.

Nicole, M., Chamberland, H., Rioux, D., Xixuan, X., Blanchette, R. A., Geiger, J. P., and Ouellette, G. B. 1995. Wood degradation by Phellinus noxius: Ultrastructure and cytochemistry. Can. J. Microbiol. 41:253-265.

Ribera, J., Tang, A., Schubert, M., Lam, R., Chu, L., Leung, M., Kwan, H., Bas, M., and Schwarze, F. 2016. In-vitro evaluation of antagonistic Trichoderma strains for eradicating Phellinus noxius in colonised wood. J. Trop. For. Sci. 28:457-468.

Sahashi, N., Akiba, M., Ishihara, M., Miyazaki, K., and Kanzaki, N. 2010. Cross inoculation tests with Phellinus noxius isolates from nine different host plants in the Ryukyu Islands, southwestern Japan. Plant Dis. 94:358-360.

Schwarze, F. W. M. R., Jauss, F., Spencer, C., Hallam, C., and Schubert, M. 2012. Evaluation of an antagonistic Trichoderma strain for reducing the rate of wood decomposition by the white rot fungus Phellinus noxius. Biol. Control 61: $160-168$.

Shih, H. D., Chung, W. C., Huang, H. C., Tseng, M., and Huang, J. W. 2013 Identification for Streptomyces padanus strain PMS-702 as a biopesticide agent. Plant Pathol. Bull. 22:145-158.

Shih, H. D., Liu, Y. C., Hsu, F. L., Mulabagal, V., Dodda, R., and Huang, J. W. 2003. Fungichromin: A substance from Streptomyces padanus with inhibitory effects on Rhizoctonia solani. J. Agric. Food Chem. 51: 95-99.

Tsai, J. N., Ann, P. J., and Hsieh, W. H. 2005. Evaluation of fungicides for suppression of three major wood-decay fungi Phellinus noxius, Rosellinia 
necatrix and Ganoderma australe in Taiwan. Plant Pathol. Bull. 14: 115-124.

Tsai, J. N., Ann, P. J., Liou, R. F., Hsieh, W. H., and Ko, W. H. 2017. Phellinus noxius: Molecular diversity among isolates from Taiwan and its phylogenetic relationship with other species of Phellinus based on sequences of the ITS region. Bot. Stud. (Taipei, Taiwan) 58:9.

Tzean, Y., Shu, P. Y., Liou, R. F., and Tzean, S. S. 2016. Development of oligonucleotide microarrays for simultaneous multi-species identification of Phellinus tree-pathogenic fungi. Microb. Biotechnol. 9:235-244.

Vilgalys, R., and Hester, M. 1990. Rapid genetic identification and mapping of enzymatically amplified ribosomal DNA from several Cryptococcus species. J. Bacteriol. 172:4238-4246.

Vogt, V., Cifuente, D., Tonn, C., Sabini, L., and Rosas, S. 2013. Antifungal activity in vitro and in vivo of extracts and lignans isolated from Larrea divaricata Cav. against phytopathogenic fungus. Ind. Crops Prod. 42: 583-586.

Vurukonda, S. S. K. P., Giovanardi, D., and Stefani, E. 2018. Plant growth promoting and biocontrol activity of Streptomyces spp. as endophytes. Int. J. Mol. Sci. 19:952.

Wang, C. Y., Lam, S. H., Tseng, L. H., and Lee, S. S. 2011. Rapid screening of lignans from Phyllanthus myrtifolius and stilbenoids from Syagrus romanzoffiana by HPLC-SPE-NMR. Phytochem. Anal. 22:352-360.

White, T. J., Bruns, T., Lee, S., and Taylor, J. 1990. Amplification and direct sequencing of fungal ribosomal RNA genes for phylogenetics. Pages 315-322 in: PCR Protocols: A Guide to Methods and Applications. M. A. Innis,
D. H. Gelfand, J. J. Sninsky, and T. J. White, eds. Academic Press, New York, NY.

Windayani, N., Juliawaty, L. D., Hakim, E. H., Ruslan, K., and Syah, Y. M. 2015. An acetylated triterpene glycoside and lignans from Phyllanthus myrtifolius and their antibacterial activities. Nat. Prod. J. 5:152-157.

Wu, J., Peng, S. L., Zhao, H. B., Tang, M. H., Li, F. R., and Chen, B. M. 2011. Selection of species resistant to the wood rot fungus Phellinus noxius. Eur. J. Plant Pathol. 130:463-467.

Wu, M. L., Chang, T. T., Jaung, L. M., Hung, T. H., Chen, C. H., and Lin, L. D. 2009. Establishment of PCR rapid detection technique for tree brown root rot disease. Q. J. Chin. For. 42:239-247.

Wu, M. L., Hsu, Y. Y., Lee, C. Y., Wu, H. D., and Hung, T. H. 2014. Application of biocontrol agents to control Phellinus noxius. Taiwan J. For. Sci. 29: S41-S53.

Wu, Z.-C., Chang, Y.-Y., Lai, Q.-J., Lin, H.-A., Tzean, S.-S., Liou, R.-F., Tsai, I. J., and Chung, C.-L. 2020. Soil is not a reservoir for Phellinus noxius. Phytopathology 110:362-369.

Zhao, L. L., He, C. P., Zheng, X. L., Fan, L. Y., and Zheng, F. C. 2011. Effect of Bacillus subtilis strain Czk1 on different rubber root pathogens and in vitro control of Colletotrichum gloeosporioides on rubber leaf. J. South. Agric. 42: 740-743.

Zhou, L. W., Ji, X. H., Vlasák, J., and Dai, Y. C. 2018. Taxonomy and phylogeny of Pyrrhoderma: A redefinition, the segregation of Fulvoderma, gen. nov., and identifying four new species. Mycologia 110:872-889. 